\title{
Analysis of Helicobacter pylori isolates from Chile: occurrence of selective type 1 Lewis b antigen expression in lipopolysaccharide
}

\author{
Eleonora Altman, ${ }^{1}$ Heriberto Fernández, ${ }^{2}$ Vandana Chandan, ${ }^{1}$ \\ Blair A. Harrison, ${ }^{1}$ Myra Wilson Schuster, ${ }^{2}$ Laura Otth Rademacher ${ }^{2}$ \\ and Claudio Toledo ${ }^{3}$ \\ ${ }^{1}$ Institute for Biological Sciences, National Research Council of Canada, Ottawa, ON K1A OR6, \\ Canada \\ ${ }^{2}$ Instituto de Microbiología Clínica, Edificio de Ciencias Biomédicas, Facultad de Medicina, \\ Universidad Austral de Chile, PO Box 567, Valdivia, Chile \\ ${ }^{3}$ Instituto de Medicina, Facultad de Medicina, Universidad Austral de Chile, PO Box 567, Valdivia, \\ Chile
}

Correspondence

Eleonora Altman

Eleonora.altman@nrc-cnrc.gc.ca

Received 27 November 2007

Accepted 19 January 2008

\begin{abstract}
Previous studies have shown that the LPS of Helicobacter pylori isolated from North American and European hosts predominantly expresses type 2 Lewis $x\left(L^{x}\right)$ and $L^{y}$ epitopes, whilst the LPS from Asian strains has the capacity to express type $1 \mathrm{Le}^{\mathrm{a}}$ and $\mathrm{Le}^{\mathrm{b}}$ structures. The aim of this study was to evaluate the expression of Le antigens and the cytotoxin-associated antigen (CagA) by $H$. pylori isolates from Chile. A total of 38 isolates were screened. The expression of Le antigens and CagA was determined by whole-cell indirect ELISA, using commercially available monoclonal anti-Le and polyclonal anti-CagA antibodies. LPS profiles of $H$. pylori isolates were assessed by gel electrophoresis and Western blotting. Expression of Le $\mathrm{e}^{\mathrm{x}}$ and/or $\mathrm{Le}^{\mathrm{y}}$ epitopes was confirmed in $32 / 38$ isolates ( $84 \%$ ), whilst 9/38 isolates (24\%) expressed type 1 Le $^{b}$ blood group determinants, in addition to type $2 \mathrm{Le}^{\mathrm{x}}$ and $\mathrm{Le}^{\mathrm{y}}$ structures. Six strains (16\%) were non-typeable. The majority of $H$. pylori strains examined were CagA-positive (83.3\%).
\end{abstract}

\section{INTRODUCTION}

Helicobacter pylori is recognized as the most common bacterial pathogen associated with chronic gastritis and peptic ulcers in humans and with increased risk of gastric adenocarcinoma and mucosa-associated lymphoid tissue lymphoma. It has been estimated to infect the gastric mucosa of more than $60 \%$ of adults over the age of 60 in industrialized countries (Dunn et al., 1997). Recent studies suggest that, in Latin America, H. pylori infection is most commonly acquired in childhood. The prevalence rates of $H$. pylori vary from 30 to $90 \%$, depending on the socioeconomic status of a given population, with most children being infected by 10 years of age (Coelho et al., 2000).

H. pylori produces several putative colonization factors, including urease, adhesin, flagella, cytotoxin-associated antigen (CagA), VacA and LPS (Covacci et al., 1999). H. pylori LPS from a number of strains from North American and European populations expresses type 2 Lewis $\mathrm{x}\left(\mathrm{Le}^{\mathrm{x}}\right)$ and $\mathrm{Le}^{\mathrm{y}}$ blood group epitopes that mimic cell-surface

Abbreviations: CagA, cytotoxin-associated antigen; HRP, horseradish peroxidase; Le, Lewis; WCE, whole-cell indirect ELISA. fucose polylactosamine-containing structures present on human gastric and tumour cells (Monteiro, 2001) (Fig. 1). Previous studies have shown a strong correlation between the expression of $\mathrm{Le}^{\mathrm{x}}$ and $\mathrm{Le}^{\mathrm{y}}$ antigens and CagA by $H$. pylori isolates contributing to inflammation and persistence (Wirth et al., 1996). More recently, the detection of type $1 \mathrm{Le}^{\mathrm{a}}$ and $\mathrm{Le}^{\mathrm{b}}$ structures in the LPS of $H$. pylori strains obtained from Asian symptomatic hosts compared with LPS from Western strains was reported (Monteiro et al., 2000) (Fig. 1). Studies on host gastric Le expression of Taiwanese H. pylori-infected patients have provided evidence for a role of gastric $\mathrm{Le}^{\mathrm{b}}$ and $\mathrm{Le}^{\mathrm{x}}$ determinants in the bacterial density of $H$. pylori in the stomach that could be correlated with clinicohistological outcome (Sheu et al., 2003). In this study, we report on the distribution of Le antigens and CagA in Chilean clinical isolates of H. pylori and the occurrence of $\mathrm{Le}^{\mathrm{b}}$ blood group antigen in the LPS of these strains.

\section{METHODS}

Patients. H. pylori was cultured from two biopsies each taken for culture from the antrum and corpus during endoscopy performed at the County Hospital and at a private clinic in Valdivia, Chile (by 


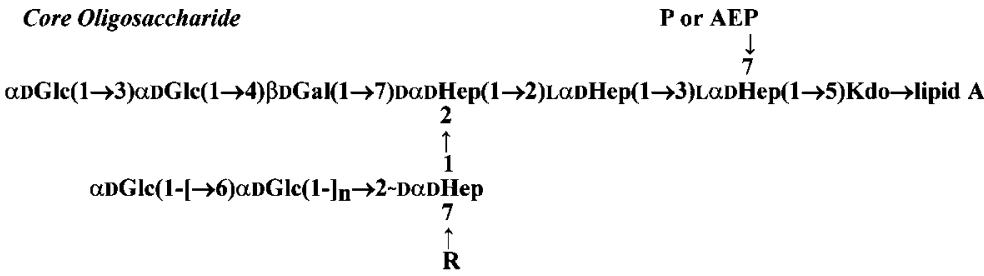

O-chain Regions

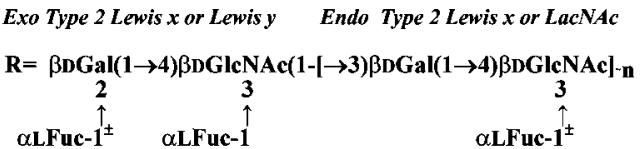

Fig. 1. Structure of the O-chain and core oligosaccharide LPS regions of Western $H$. pylori strains. Reproduced from Monteiro et al. (2000) by permission of Oxford University Press. The O-chain is covalently linked to the core oligosaccharide through a side chain DD-Hep. Kdo, 3-deoxy-D-manno-oct-2-ulosonic acid; AEP, 2-aminoethylphosphate; $\mathrm{P}$, phosphate.
C. T.). Written informed consent to participate in this study was obtained from all patients. The Ethics Committee of the Facultad de Medicina, Universidad Austral de Chile, approved this study. Of the 196 biopsy samples collected, 59 were identified as $H$. pylori (isolation frequency $30.1 \%$ ). The median age of patients was 51.4 years (range $17-87$ years) with a male-to-female ratio of 0.51 (20 males and 39 females). Thirteen adult patients had gastritis, ten had gastric ulcers, six had oesophagitis, two had reflux and five had duodenal ulcers. Fourteen isolates were from patients without lesions and nine isolates were from patients with no registered symptoms. A total of $38 \mathrm{H}$. pylori isolates were chosen at random and examined in the present study.

Culture. Biopsy samples were homogenized and inoculated onto antibiotic-supplemented (Oxoid Dent Supplement) blood agar plates and incubated at $37{ }^{\circ} \mathrm{C}$ under microaerophilic conditions for 4 5 days. Characteristic colonies were tested for culture purity by a urease assay and Gram staining. Single colonies were propagated further, and frozen stocks were prepared using brain heart infusion broth containing $20 \%$ glycerol. They were stored at $-80{ }^{\circ} \mathrm{C}$. H. pylori isolates were cultured at $37{ }^{\circ} \mathrm{C}$ on Columbia blood agar (Difco Laboratories) containing $7 \%$ defibrinated horse blood in a microaerophilic environment for $48 \mathrm{~h}$.

Whole-cell indirect ELISA (WCE). H. pylori strains were cultivated on plates as described previously (Logan et al., 2000). Cells were harvested and washed with $5 \mathrm{ml} 10 \mathrm{mM}$ PBS ( $\mathrm{pH}$ 7.4) per plate. Following centrifugation $\left(5000 \mathrm{~g}, 5 \mathrm{~min}, 4^{\circ} \mathrm{C}\right)$, pellets were suspended in $25 \mathrm{ml}$ PBS to give a final concentration of $10^{8}$ cells $\mathrm{ml}^{-1}$. Microtitre plates (ICN) were coated with $100 \mu \mathrm{l}$ bacterial suspension and incubated overnight at $4{ }^{\circ} \mathrm{C}$. The bacteria were removed and the wells were fixed for $5 \mathrm{~min}$ with methanol and then dried for $15 \mathrm{~min}$. The wells were blocked with $200 \mu \mathrm{l}$ milk diluent/blocking solution (MDB; KPL) for $2 \mathrm{~h}$ at $37{ }^{\circ} \mathrm{C}$. Subsequently, the wells were incubated for $2 \mathrm{~h}$ at $37^{\circ} \mathrm{C}$ with $100 \mu \mathrm{l}$ anti-Le $\mathrm{Le}^{\mathrm{a}}$, $-\mathrm{Le}^{\mathrm{b}}$, $-\mathrm{Le}^{\mathrm{x}}$ or $-\mathrm{Le}^{\mathrm{y}}$ monoclonal antibody (mAb) solution (Signet Laboratories) diluted 1:200 in MDB or rabbit anti-CagA antibody (Austral Biologicals) diluted $1: 100$ in MDB. Corresponding secondary antibody, either horseradish peroxidase (HRP)-conjugated anti-mouse IgG + IgM or HRPconjugated anti-rabbit IgG (Cedarlane Laboratories) diluted 1:1000 in MDB, was added and the plates were incubated for $1 \mathrm{~h}$ at room temperature. Between incubation steps, the wells were washed four times with PBS. After a final washing step, the substrate $3,3^{\prime}, 5,5^{\prime}$ tetramethylbenzidene (KPL) was added and the reaction was stopped with $1 \mathrm{M}$ phosphoric acid. The $A_{450}$ was determined using a microtitre plate reader (Dynatech). Non-specific background values were determined as $A_{450}$ of the negative-control wells containing bacterial cells, secondary antibody conjugate and substrate. These $A_{450}$ values were $\leqslant 0.2$. Values of $A_{450}<0.2$ were classified as negative and values of $A_{450} \geqslant 0.2$ were classified as positive reactions. To ensure plate-to-plate consistency, $H$. pylori strain 26695 cells were used as a positive control for $\mathrm{Le}^{\mathrm{x}}, \mathrm{Le}^{\mathrm{y}}$ and CagA. Assays did not vary by more than $10 \%$

Electrophoresis and Western blotting. SDS-PAGE was performed with a mini-slab apparatus (Bio-Rad) using the Laemmli method. LPS samples were prepared from whole cells according to a previously described method (Logan \& Trust, 1984) and equivalent amounts were loaded in each lane and stained according to Tsai \& Frasch (1982) or transferred to nitrocellulose for immunological detection with anti-Le ${ }^{\mathrm{x}}$ and anti-Le $\mathrm{e}^{\mathrm{y}} \mathrm{mAbs}$ as described previously (Logan et al., 2000). To ensure consistency, H. pylori strain 26695 was used as a positive control for anti-Le ${ }^{\mathrm{x}}$ and anti-Le ${ }^{\mathrm{y}}$ mAbs. For detection of $\mathrm{Le}^{\mathrm{b}}$ in bacterial whole-cell samples, nitrocellulose membranes were blocked with $1 \%$ skimmed milk in $10 \mathrm{mM}$ PBS ( $\mathrm{pH}$ 7.4) overnight at $4{ }^{\circ} \mathrm{C}$. Subsequently, membranes were incubated with anti-Le ${ }^{\mathrm{b}} \mathrm{mAb}$ solution diluted $1: 100$ in $10 \mathrm{mM}$ PBS (pH 7.4) overnight at $4{ }^{\circ} \mathrm{C}$. Corresponding secondary antibody, HRP-conjugated anti-mouse IgG + IgM diluted 1:3000 in $10 \mathrm{mM}$ PBS ( $\mathrm{pH} 7.4$ ), was added and the nitrocellulose membranes were incubated for $1 \mathrm{~h}$ at room temperature. The membranes were washed three times with $10 \mathrm{mM}$ PBS ( $\mathrm{pH}$ 7.4) between the incubation steps and developed using SuperSignal West Pico Chemiluminescent substrate (Pierce) following the manufacturer's instructions. The synthetic $\mathrm{Le}^{\mathrm{b}}$ antigen $\mathrm{Le}^{\mathrm{b}}-$ hexasaccharide-BSA (lacto- $N$-difucohexaose I-BSA or LNDFHIBSA; V-Labs) was used as a positive control. Whole cells of the $\mathrm{Le}^{\mathrm{y}}$ antigen-expressing $H$. pylori Sydney (SS1) strain were used as a negative control in Western blots to ensure specificity of anti-Le ${ }^{b}$ mAbs. In no case did we find any cross-reactivity with $\mathrm{Le}^{\mathrm{y}}$ for the $\mathrm{Le}^{\mathrm{b}}$ specific mAbs under Western blot conditions.

\section{RESULTS AND DISCUSSION}

In the present study, we examined $H$. pylori isolates from Chile by WCE, gel electrophoresis and Western blotting. Similar approaches have been applied previously to the analysis of $H$. pylori isolates from gastric biopsies (Rasko et al., 2000) and typing of $H$. pylori isolates from different geographical regions (Simoons-Smit et al., 1996). However, the distribution of Le antigens in $H$. pylori strains from Latin America has not been examined.

Screening of 38 Chilean isolates of $H$. pylori by WCE resulted in the detection of $\mathrm{Le}^{\mathrm{x}}$ and/or $\mathrm{Le}^{\mathrm{y}}$ epitopes in 32 strains. Co-expression of $\mathrm{Le}^{\mathrm{x}}$ and $\mathrm{Le}^{\mathrm{y}}$ antigens was detected in 14 strains. Three isolates expressed only $\mathrm{Le}^{\mathrm{x}}$ antigen 
(7.9\%), whilst exclusive $\mathrm{Le}^{\mathrm{y}}$ expression was identified in six isolates $(15.8 \%)$. Le ${ }^{\mathrm{b}}$ antigen was identified in nine isolates (23.7\%), either co-expressed with $\mathrm{Le}^{\mathrm{x}}$ and $\mathrm{Le}^{\mathrm{y}}$ (four isolates) or just with $\mathrm{Le}^{\mathrm{y}}$ (five isolates) (Table 1). No isolate expressing $\mathrm{Le}^{\mathrm{a}}$ antigen was identified. Expression of the CagA protein was detected in $83.3 \%$ of isolates studied. Six isolates $(15.8 \%)$ contained no identifiable Le antigen and were non-typeable. A previous survey of $H$. pylori isolates from different geographical regions by SimoonsSmit et al. (1996) reported a similar distribution of typeable (85\%) and non-typeable strains (15\%), with most of the non-typeable isolates originating from China.

We were unable to demonstrate a significant correlation between the expressed Le antigen type and the associated disease (Table 1). Previous studies by Wirth et al. (1996) suggested that Le expression appeared to be more common among $H$. pylori isolates from patients with ulcer disease. In the present study, 9/10 analysed isolates from patients with ulcer disease (five gastric ulcer isolates and five

Table 1. Expression of Le and CagA antigens in $H$. pylori isolates from Chile

\begin{tabular}{|c|c|c|c|c|c|c|c|}
\hline Strain & Disease & $\mathrm{Le}^{\mathrm{x}}$ & $\mathrm{Le}^{\mathrm{y}}$ & $\mathrm{Le}^{\mathrm{a}}$ & $\mathrm{Le}^{\mathrm{b}}$ & CagA & O-chain* \\
\hline 004CL & Gastric ulcer & 1.065 & - & - & - & 0.957 & $+\left(\mathrm{Le}^{\mathrm{x}}\right)$ \\
\hline 006CL & Duodenal ulcer & - & - & - & - & 0.989 & - \\
\hline $011 \mathrm{CL}$ & Dyspepsia & - & 1.282 & - & - & 0.426 & $+\left(\mathrm{Le}^{\mathrm{y}}\right)$ \\
\hline 018CL & Dyspepsia & - & - & - & - & - & + \\
\hline $023 \mathrm{CL}$ & Duodenal ulcer & - & 0.787 & - & - & - & $+\left(\mathrm{Le}^{\mathrm{y}}\right)$ \\
\hline 026CL & Dyspepsia & 0.378 & 1.303 & - & 0.556 & 0.491 & $+\left(\mathrm{Le}^{\mathrm{y}}, \mathrm{Le}^{\mathrm{b}}\right)$ \\
\hline 027CL & Dyspepsia & - & - & - & - & - & - \\
\hline 029CL & Duodenal ulcer & - & 1.140 & - & - & - & $+\left(\mathrm{Le}^{\mathrm{y}}\right)$ \\
\hline 060CL & Duodenal ulcer & 0.290 & 0.993 & - & - & 1.590 & $+\left(\mathrm{Le}^{\mathrm{y}}\right)$ \\
\hline 066CL & Gastric ulcer and reflux & - & 0.308 & - & - & 1.828 & $+\left(\mathrm{Le}^{\mathrm{y}}\right)$ \\
\hline 068CL & Oesophagitis & 0.958 & 0.701 & - & - & 1.442 & $+\left(\mathrm{Le}^{\mathrm{x}}, \mathrm{Le}^{\mathrm{y}}\right)$ \\
\hline 069CL & Gastritis & - & - & $\mathrm{ND}$ & - & $\mathrm{ND}$ & $\mathrm{ND}$ \\
\hline 076CL & Gastritis & 1.724 & 0.343 & - & - & 1.770 & $+\left(\mathrm{Le}^{\mathrm{x}}\right)$ \\
\hline 077CL & Gastric ulcer & 1.769 & 0.314 & - & - & 1.227 & $+\left(\mathrm{Le}^{\mathrm{x}}\right)$ \\
\hline $082 \mathrm{CL}$ & Gastritis & 1.882 & 1.024 & - & - & 1.949 & $+\left(\mathrm{Le}^{\mathrm{x}}, \mathrm{Le}^{\mathrm{y}}\right)$ \\
\hline 084CL & Oesophagitis & 0.768 & - & $\mathrm{ND}$ & - & $\mathrm{ND}$ & $\mathrm{ND}$ \\
\hline 085CL & Oesophagitis & 1.299 & - & - & - & 0.345 & $+\left(\mathrm{Le}^{\mathrm{x}}\right)$ \\
\hline 094CL & Gastritis & 0.249 & 0.454 & - & - & 0.636 & $+\left(\mathrm{Le}^{\mathrm{y}}\right)$ \\
\hline 098CL & Dyspepsia & 1.363 & 0.377 & - & - & 1.514 & $+\left(\mathrm{Le}^{\mathrm{x}}\right)$ \\
\hline $151 \mathrm{CL}$ & Dyspepsia, weight loss & 0.587 & 1.131 & - & - & 1.504 & $+\left(\mathrm{Le}^{\mathrm{y}}\right)$ \\
\hline $153 \mathrm{CL}$ & Dyspepsia & - & 0.896 & - & 1.243 & 1.575 & $+\left(\mathrm{Le}^{\mathrm{b}}\right)$ \\
\hline $160 \mathrm{CL}$ & Dyspepsia & - & - & - & - & 0.361 & + \\
\hline $217 \mathrm{CL}$ & Dyspepsia & 1.360 & 0.530 & - & - & 1.586 & + \\
\hline $240 \mathrm{CL}$ & Duodenal ulcer & 0.256 & 0.374 & - & 0.527 & 0.436 & + \\
\hline
\end{tabular}

ND, Not determined.

${ }^{*}$ SDS-PAGE analysis was performed on proteinase K-treated bacterial cells. The Le antigen content of the O-chain is shown in parentheses and is based on Western blot analysis (see Figs 2 and 3). 
duodenal ulcer isolates) tested positive for at least one Le determinant. However, the expression of at least one Le determinant was also confirmed in $24 / 28(85.7 \%)$ surveyed isolates of non-ulcer origin (16 dyspepsia isolates, six gastritis isolates, four oesophagitis isolates, one antropyloric deformation isolate and one gastro-oesophagic reflux isolate). Interestingly, four of the nine $\mathrm{Le}^{\mathrm{b}}$-expressing isolates identified in this study originated from dyspepsia patients (Table 1). Four of six non-typeable strains also originated from dyspepsia patients. The prognostic significance of these findings remains to be established. $\mathrm{Le}^{\mathrm{b}}$ expression was also found in two isolates from patients with ulcer disease (one duodenal ulcer and one gastric ulcer isolate) in combination with either type $2 \mathrm{Le}^{\mathrm{x}}$ and/or $\mathrm{Le}^{\mathrm{y}}$ expression. Exclusive $\mathrm{Le}^{\mathrm{x}}$ expression was confirmed in $2 / 4$ isolates from patients with oesophagitis and one gastric ulcer isolate, whilst exclusive $\mathrm{Le}^{\mathrm{y}}$ expression was established in six isolates $(6 / 38,15.8 \%)$ from patients with diverse clinical symptoms and associated diseases (Table 1).

WCE findings were corroborated by SDS-PAGE and Western blot analyses with anti-Lee ${ }^{\mathrm{x}}$, anti-Le $\mathrm{L}^{\mathrm{y}}$ and anti-Le ${ }^{\mathrm{b}}$ mAbs. As expected, most typeable isolates exhibited typical high-molecular-mass ladder-like patterns indicative of smooth-form LPS (Table 1, Figs 2 and 3). Both WCE (Table 1) and silver staining revealed that strains 104CL (Fig. 2a, panel iii), 153CL (Fig. 2a, panel iv) and 217CL (Fig. 2a, panel iv) possessed an $\mathrm{O}$-chain polysaccharide expressing $\mathrm{Le}^{\mathrm{y}}$ and/or Le ${ }^{\mathrm{x}}$ antigens, although their presence could not be detected by Western blotting with their respective anti-Le mAbs. The detection of a highmolecular-mass ladder-like pattern by silver staining in strains 018CL (Fig. 2a, panel i) and 160CL (Fig. 2a, panel iv), which tested negative for the presence of Le antigens by WCE and Western blotting, was indicative of the expression of an additional antigen that did not react with anti-Le mAbs (Table 1, Fig. 2).

Previous attempts to carry out Western blotting experiments with anti-Le ${ }^{\mathrm{b}}$ mAbs on $H$. pylori whole-cell samples were unsuccessful, and it was assumed that these antibodies did not react under Western blot conditions (Monteiro et al., 1998). However, Holgersson \& Löfling (2006) have shown recently that the detection of $\mathrm{Le}^{\mathrm{b}}$ antigens on glycoconjugates can be achieved with anti-Le $\mathrm{e}^{\mathrm{b}} \mathrm{mAbs}$ in a Western blot format when a chemiluminescent substrate is utilized. By adopting a similar approach, we were able to demonstrate the recognition of $\mathrm{Le}^{\mathrm{b}}$ epitope by anti-Le ${ }^{\mathrm{b}}$ mAbs under Western blot conditions in 6/9 H. pylori isolates tested. Three $\mathrm{Le}^{\mathrm{b}}$-containing $H$. pylori isolates, 049CL, 104CL and 240CL, did not react in the Western blot format but were positive for the presence of $\mathrm{Le}^{\mathrm{b}}$ antigen in WCE (Table 1). It is possible that in these three strains $\mathrm{Le}^{\mathrm{b}}$ epitope is linked directly to the core region of LPS and is conformationally inaccessible. The silverstaining pattern of $\mathrm{Le}^{\mathrm{b}}$-containing $H$. pylori strain $240 \mathrm{CL}$ (Fig. 2a, panel iv) was consistent with the presence of a high-molecular-mass non-Le structure, as this strain had a low content of $\mathrm{Le}^{\mathrm{y}}$ and $\mathrm{Le}^{\mathrm{x}}$ antigens according to the WCE results and tested negative for $\mathrm{Le}^{\mathrm{y}}$ and $\mathrm{Le}^{\mathrm{x}}$ antigens by Western blotting (Fig. 2b, panel iv, and Fig. 2c, panel iv). The presence of the $\mathrm{O}$-chain in two other $\mathrm{Le}^{\mathrm{b}}$-containing strains, 049CL (Fig. 2a, panel ii) and 104CL (Fig. 2a, panel iii), was confirmed by silver staining although the signal was faint. Only one of these strains, 049CL, tested positive for the presence of Le ${ }^{\mathrm{y}}$ antigen by Western blotting (Fig. 2c, panel ii). It is plausible that $\mathrm{O}$-chain polysaccharide in the LPS of these strains is composed of non-fucosylated or partially fucosylated type $2 \mathrm{~N}$-acetyllactosamine repeating units capped by $\mathrm{Le}^{\mathrm{y}}$ and/or Le $\mathrm{Le}^{\mathrm{x}}$ antigens (Fig. 1). These structures were previously found to be co-expressed with type $1 \mathrm{Le}^{\mathrm{b}}$ antigens in $H$. pylori LPS from Asian hosts (Monteiro et al., 2000). Further structural studies are needed to confirm these findings.

Silver staining and Western blotting with anti-Le ${ }^{\mathrm{b}} \mathrm{mAbs}$ revealed significant variations in the $\mathrm{O}$-chain length of $\mathrm{Le}^{\mathrm{b}}$-containing isolates (Fig. 3). In H. pylori strains 016CL, 099CL and 109CL, the Le $\mathrm{e}^{\mathrm{b}}$ epitope was associated with short O-chains, whilst in strains $048 \mathrm{CL}$ and 153CL, the $\mathrm{Le}^{\mathrm{b}}$ structure was capping longer O-chains. One strain, 026CL, appeared to produce a very long $\mathrm{O}$-chain capped by $\mathrm{Le}^{\mathrm{b}}$ antigen (Fig. 3).

Previous studies have addressed the distribution of Le antigens in $H$. pylori isolates from different geographical regions, including North America, Europe and Asia. These investigations have identified type $2 \mathrm{Le}^{\mathrm{x}}$ and $\mathrm{Le}^{\mathrm{y}}$ antigens as the most frequently encountered antigens in $H$. pylori LPS (Simoons-Smit et al., 1996; Wirth et al., 1996). Recently, expression of type $1 \mathrm{Le}^{\mathrm{a}}$ and $\mathrm{Le}^{\mathrm{b}}$ antigens in LPS from Asian $H$. pylori isolates has been demonstrated, either solely or in combination with type $2 \mathrm{Le}$ and/or $\mathrm{N}$-acetyllactosamine epitopes (Monteiro et al., 2000). The tendency for expression of type 1 Le blood group antigens in $H$. pylori LPS from Asian hosts compared with Western populations is not well understood but is thought to be related to the host Le phenotype (Wirth et al., 1997).

We were able to demonstrate the presence of $\mathrm{Le}^{\mathrm{b}}$ antigen in the LPS of $H$. pylori strains from Chile by two methods, WCE and Western blotting. The results of the Western blot analysis suggested further structural diversity among type 1 $\mathrm{Le}^{\mathrm{b}}$ antigen-containing $H$. pylori strains associated with the presence of capping $\mathrm{Le}^{\mathrm{b}}$ epitopes on either short or long $\mathrm{O}$ chain LPSs. To our knowledge, this is the first instance in which this blood group epitope has been identified in $H$. pylori strains from Latin America. Previous studies of $H$. pylori isolates obtained from various geographical regions have shown type $1 \mathrm{Le}^{\mathrm{b}}$ antigen expression in $13 \%$ of isolates (Wirth et al., 1996). Of these, only three strains were from Latin America (Peru), and a correlation between geographical origin and observed Le antigen type was not reported.

Our study examined the correlation between CagA expression and Le status. H. pylori strains isolated from both symptomatic and asymptomatic patients were examined. In a previous study by Cover et al. (1995), the 
(a)

(i)

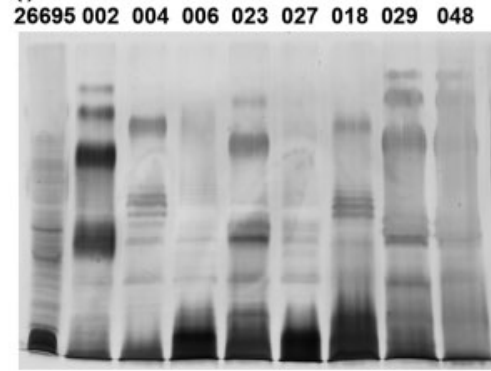

(ii)

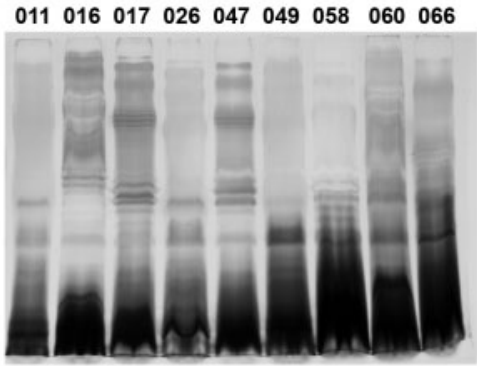

(iii)

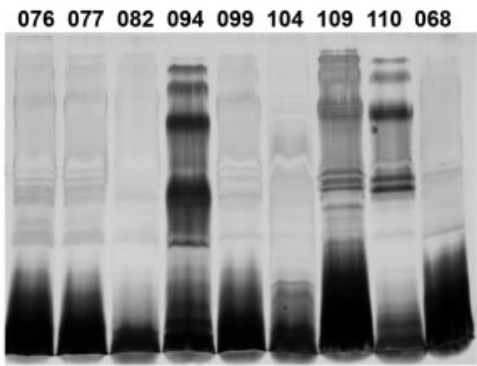

(iv)

$\begin{array}{lllllllll}085 & 098 & 101 & 113 & 114 & 151 & 153160 & 217 & 240\end{array}$

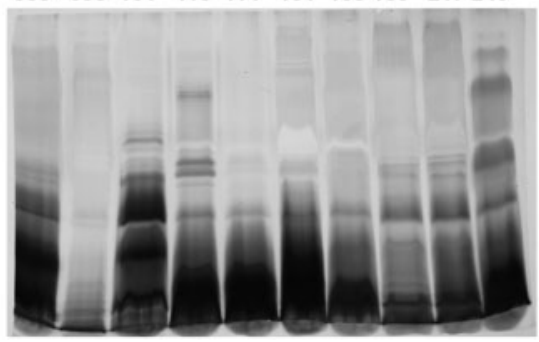

(b)

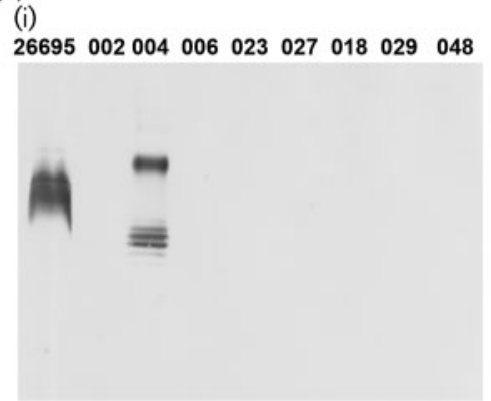

(ii)

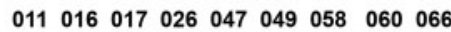

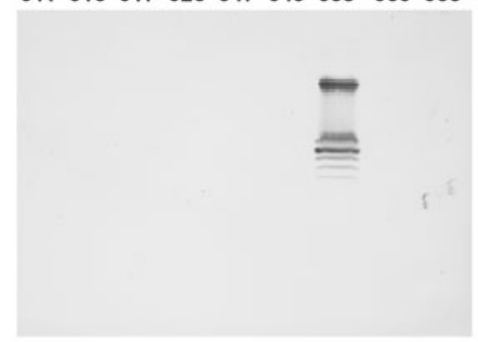

(iii)

$\begin{array}{lllllllll}076 & 077 & 082 & 094 & 099 & 104 & 109 & 110 & 068\end{array}$

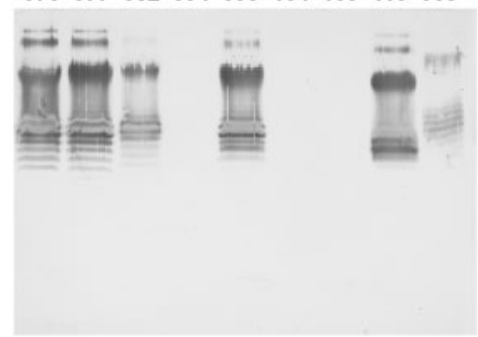

(iv)

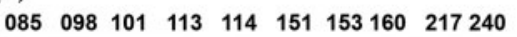

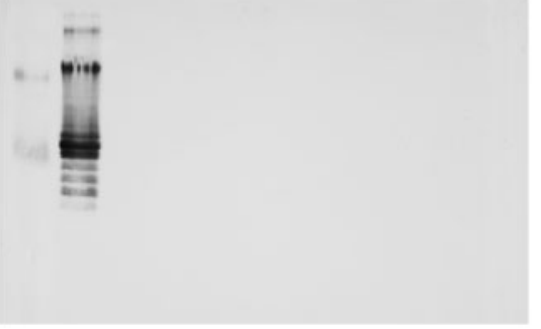

(c)

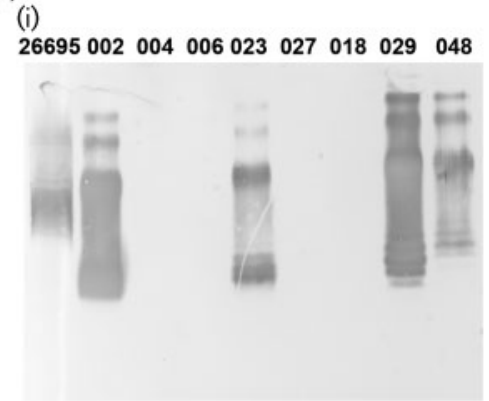

(ii)

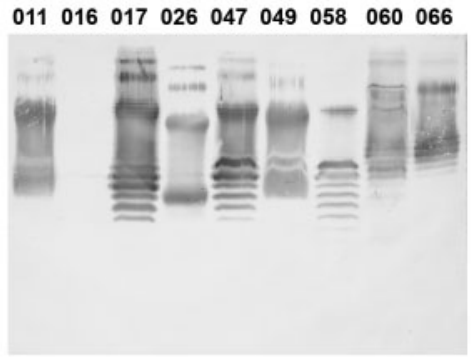

(iii)

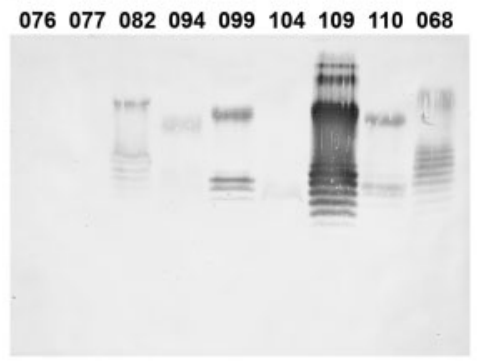

(iv)

$085098101 \quad 113 \quad 114 \quad 151 \quad 153 \quad 160 \quad 217 \quad 240$

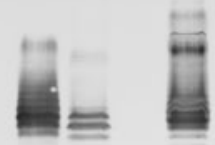

Fig. 2. Silver-staining and Western blots of proteinase K-treated whole cells of $H$. pylori. (a) Silver-stained $12.5 \%$ SDSpolyacrylamide gels. $H$. pylori strain 26695 was used as a positive control; 002 denotes strain $002 \mathrm{CL}$, etc. (b, c) Corresponding Western blots using anti-Le $\mathrm{xAb}^{\mathrm{x}}$ at a $1: 150$ dilution (b) and anti-Le $\mathrm{mAb}$ at a $1: 500$ dilution (c).

proportion of $\mathrm{CagA}^{+}$H. pylori isolates from duodenal ulcer patients was found to be $87.5 \%$ based on combined bacteriological and serological testing. Wirth et al. (1996) found that cagA was expressed by $97 \%$ of isolates, of which $75.7 \%$ were $\mathrm{CagA}^{+}$as determined by WCE. In the present study, we observed a higher number of $\mathrm{CagA}^{+}$strains. No correlation between the absence of CagA expression and Le antigen type was found.
It has been shown that, whilst $H$. pylori infection is common among the Chilean adult population, seroconversion occurs early in life and is related directly to socioeconomic status (Hopkins et al., 1993). Increased seroprevalence of $H$. pylori in children of lower socioeconomic groups has been reported in other Latin American countries, such as Brazil (Oliveira et al., 1994), Peru (Klein et al., 1994), Colombia (Goodman et al., 1996) 
(a)

Std SS1 016026048099109153

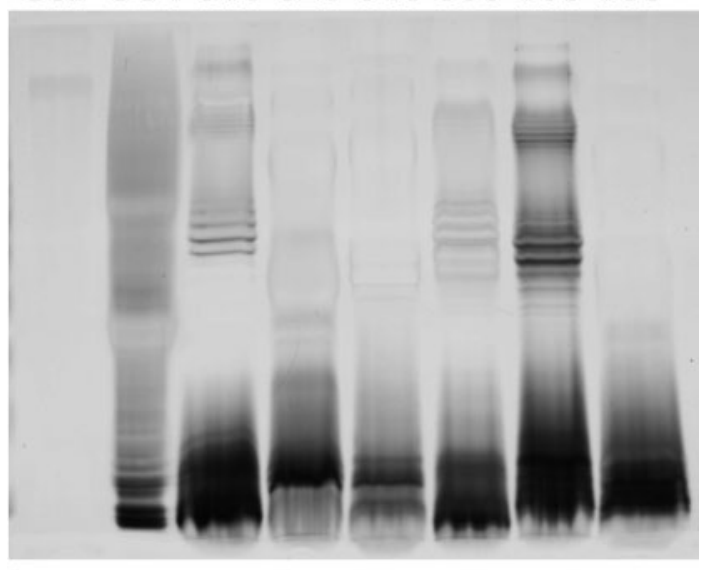

(b)

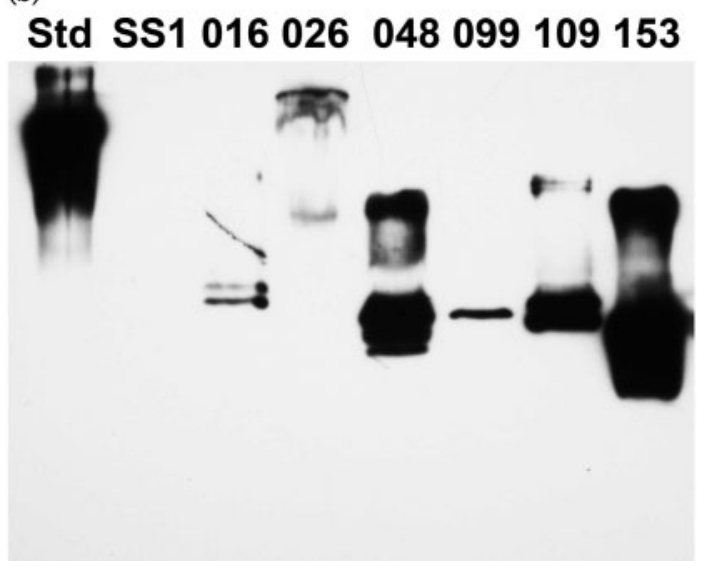

Fig. 3. Silver-stained $12.5 \%$ SDS-polyacrylamide gels (a) and Western blots (b) of proteinase K-treated whole cells of $H$. pylori $\mathrm{Le}^{\mathrm{b}}$-containing isolates. The Western blot used anti-Le ${ }^{\mathrm{b}} \mathrm{mAb}$ at a $1: 100$ dilution. Std, Le ${ }^{b}$-hexasaccharide-BSA used as a positive control; SS1, H. pylori strain SS1 used as a negative control; 016 denotes 016CL, etc. (see Methods for details).

and Mexico (Castillo-Rojas et al., 2004). Consumption of uncooked vegetables and shellfish has been found to correlate with $H$. pylori seropositivity, as have modes of vegetable washing and swimming near contaminated beaches (Hopkins et al., 1993). Evaluation of the Le antigen distribution in $H$. pylori isolates from Chile could be applied to general epidemiological and population studies to assess the effectiveness of $H$. pylori prevention and eradication strategies.

\section{ACKNOWLEDGEMENTS}

The authors thank Dr Jean-Marc Gabastou from the Pan American Health Organization (PAHO) for support and encouragement of these studies. We thank Tom Devecseri for assistance with photography. Financial support from the Canadian International Development Agency (CIDA) in collaboration with the International
Development Research Centre (IDRC), the Canadian Institutes of Health Research (CIHR) and Health Canada (HC) through the Global Health Research Initiative (GHRI) operational research grants for the Canadian International Immunization Initiative (CIII2) (File: 102172-006) (to E. A. and H.F.) and the Research and Development Bureau-Universidad Austral de Chile (Grant DID-UACH S-2006-25) (to L. O. R., M.W.S. and H.F.) is gratefully acknowledged.

\section{REFERENCES}

Castillo-Rojas, G., Mazari-Hiriart, M. \& López-Vidal, Y. (2004). Helicobacter pylori: focus on CagA and VacA major virulence factors. Salud Publica Mex 46, 538-548.

Coelho, L. G. V., León-Barúa, R., Quigley, E. M. M. \& Representatives of the Latin-American National Gastroenterological Societies affiliated with the Inter-American Association of Gastroenterology (AIGE) (2000). Latin-American consensus conference on Helicobacter pylori infection. Am J Gastroenterol 95, 2688-2691.

Covacci, A., Telford, J. L., Del Giudice, G., Parsonnet, J. \& Rappuoli, R. (1999). Helicobacter pylori virulence and genetic geography. Science 284, 1328-1333.

Cover, T. L., Glupczynski, Y., Lage, A. P., Burette, A., Tummuru, M. K. R., Perez-Perez, G. I. \& Blaser, M. J. (1995). Serological detection of infection with cagA ${ }^{+}$Helicobacter pylori strains. J Clin Microbiol 33, 1496-1500.

Dunn, B. E., Cohen, H. \& Blaser, M. J. (1997). Helicobacter pylori. Clin Microbiol Rev 10, 720-741.

Goodman, K. J., Correa, P., Tenganá-Aux, H. J., Ramírez, H., DeLany, J. P., Pepinosa, O. G., Quiñonez, M. L. \& Collazos-Parra, T. (1996). Helicobacter pylori infection in the Colombian Andes: a populationbased study of transmission pathways. Am J Epidemiol 144, 290-299.

Holgersson, J. \& Löfling, J. (2006). Glycosyltransferases involved in type 1 chain and Lewis antigen biosynthesis exhibit glycan and core chain specificity. Glycobiology 16, 584-593.

Hopkins, R. J., Vial, P. A., Ferreccio, C., Ovalle, J., Prado, P., Sotomayor, V., Russell, R. G., Wasserman, S. S. \& Morris, J. G., Jr (1993). Seroprevalence of Helicobacter pylori in Chile: vegetables may serve as one route of transmission. J Infect Dis 168, 222-226.

Klein, P. D., Gilman, R. H., Leon-Barua, R., Diaz, F., O’Brien Smith, E. \& Graham, D. Y. (1994). The epidemiology of Helicobacter pylori in Peruvian children between 6 and 30 months of age. Am J Gastroenterol 89, 2196-2200.

Logan, S. M. \& Trust, T. J. (1984). Structural and antigenic heterogeneity of lipopolysaccharides of Campylobacter jejuni and Campylobacter coli. Infect Immun 45, 210-216.

Logan, S. M., Conlan, J. W., Monteiro, M. A., Wakarchuk, W. W. \& Altman, E. (2000). Functional genomics of Helicobacter pylori: identification of a $\beta-1,4$ galactosyltransferase and generation of mutants with altered lipopolysaccharide. Mol Microbiol 35, 1156-1167.

Monteiro, M. A. (2001). Helicobacter pylori: a wolf in sheep's clothing: the glycotype families of Helicobacter pylori lipopolysaccharides expressing histo-blood groups: structure, biosynthesis, and role in pathogenesis. Adv Carbohydr Chem Biochem 57, 99-158.

Monteiro, M. A., Chan, K. H. N., Rasko, D. A., Taylor, D. E., Zheng, P. Y., Appelmelk, B. J., Wirth, H.-P., Yang, M., Blaser, M. J. \& other authors (1998). Simultaneous expression of type 1 and type 2 Lewis blood group antigens by Helicobacter pylori lipopolysaccharides. J Biol Chem 273, 11533-11543.

Monteiro, M. A., Zheng, P., Ho, B., Yokota, S., Amano, K., Pan, Z., Berg, D. E., Chan, K. H., MacLean, L. L. \& Perry, M. B. (2000). 
Expression of histo-blood group antigens by lipopolysaccharides of Helicobacter pylori strains from Asian hosts: the propensity to express type 1 blood-group antigens. Glycobiology 10, 701-713.

Oliveira, A. M. R., Queiroz, D. M. M., Rocha, G. A. \& Mendes, E. N. (1994). Seroprevalence of Helicobacter pylori infection in children of low socioeconomic level in Belo Horizonte, Brazil. Am J Gastroenterol 89, 2201-2204.

Rasko, D. A., Wilson, T. J. M., Zopf, D. \& Taylor, D. E. (2000). Lewis antigen expression and stability in Helicobacter pylori isolated from serial gastric biopsies. J Infect Dis 181, 1089-1095.

Sheu, B.-S., Sheu, S.-M., Yang, H.-B., Huang, A.-H. \& Wu, J.-J. (2003).

Host gastric Lewis expression determines the bacterial density of Helicobacter pylori in babA2 genopositive infection. Gut 52, 927-932.
Simoons-Smit, I. M., Appelmelk, B. J., Verboom, T., Negrini, R., Penner, J. L., Aspinall, G. O., Moran, A. P., Fei, S. F., Bi-Shan, S. \& other authors (1996). Typing of Helicobacter pylori with monoclonal antibodies against Lewis antigens in lipopolysaccharide. J Clin Microbiol 34, 2196-2200.

Tsai, C. M. \& Frasch, C. E. (1982). A sensitive silver stain for detecting lipopolysaccharide in polyacrylamide gels. Anal Biochem 119, 115-119.

Wirth, H.-P., Yang, M., Karita, M. \& Blaser, M. J. (1996). Expression of the human cell surface glycoconjugates Lewis $\mathrm{X}$ and Lewis $\mathrm{Y}$ by Helicobacter pylori isolates is related to cagA status. Infect Immun 64, 4598-4605.

Wirth, H.-P., Yang, M., Peek, R. M., Jr, Tham, K. T. \& Blaser, M. J. (1997). Helicobacter pylori Lewis expression is related to the host Lewis phenotype. Gastroenterology 113, 1091-1098. 